\title{
Non-Destructive Characterization, Inspection, Failure Analysis of Advanced Components and Sensors with a High Resolution and High Contrast Micro XCT System
}

\author{
S.H. LAU* \\ Xradia, Inc., Concord, CA 94520, USA \\ AND A. KOWALCZYK ${ }^{\dagger}$ \\ LOT-Oriel, 41-710, Ruda Śląska, Poland
}

\section{Introduction}

3D X-ray microtomography (Micro XCT) can non-destructively characterize, inspect and solve many failure analysis problems associated with the manufacture of advanced materials, components, finished products, sensors for the military and industry. Our novel high resolution and high contrast micro $\mathrm{CT}$ can be used to visualize defects at the micrometer and sub-micrometer length scales, typically encountered in the manufacturing and development of advanced sensors and polymer composites.

Computer tomography (CT) has been used for several years in the medical community for non-invasive X-ray imaging of the human anatomy. The same technique is applied to non-destructive inspections of part and components where the object can be viewed in $3 \mathrm{D}$ and selected CT virtual slices (cross-sections) can be made at different planes to reveal the internal structures.

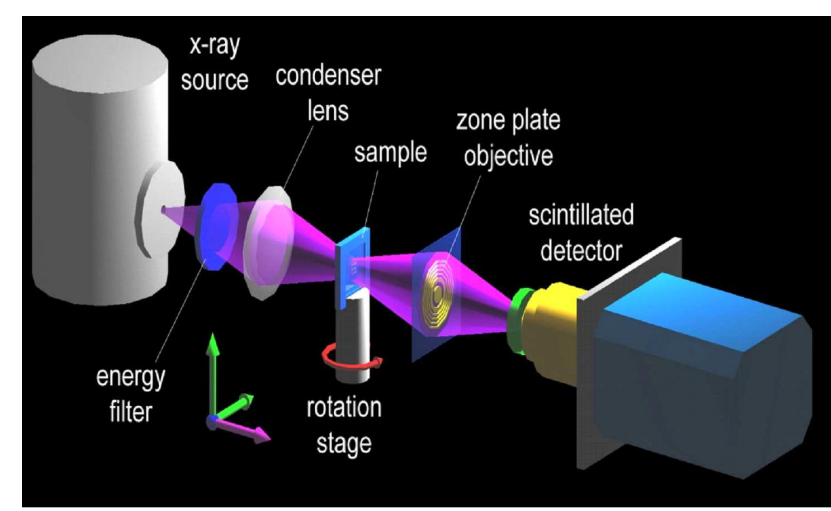

Fig. 1. Schematic of the MicroXCT.
Micro XCT has the advantage over conventional imaging tools such as optical microscopy and electron microscopy since it can image surface and buried structures without sample preparation, vacuum requirement or physical deprocessing.

\section{Results}

The schematic of the Xradia MicroXCT system configuration is performed below (Fig. 1).

High resolution is achieved by zooming in the region of interest at higher magnification. Other potential applications of the tool include the examination of overt or covert sensors, components, smart materials of military significance from friendly or hostile nations, without physical cross-sectioning or material deprocessing. Examples performed below (Figs. 2 and 3).

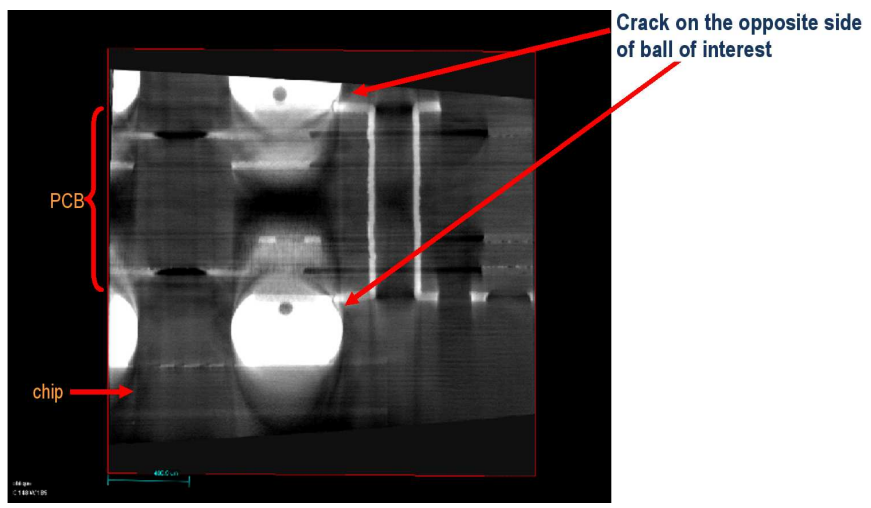

Fig. 2. CT slice (virtual section at $x-y$ plane) showing cracs just below solder balls [1].

\footnotetext{
* e-mail: shlau@xradia.com

$\dagger$ e-mail: kowalczyk@lot-oriel.pl
} 


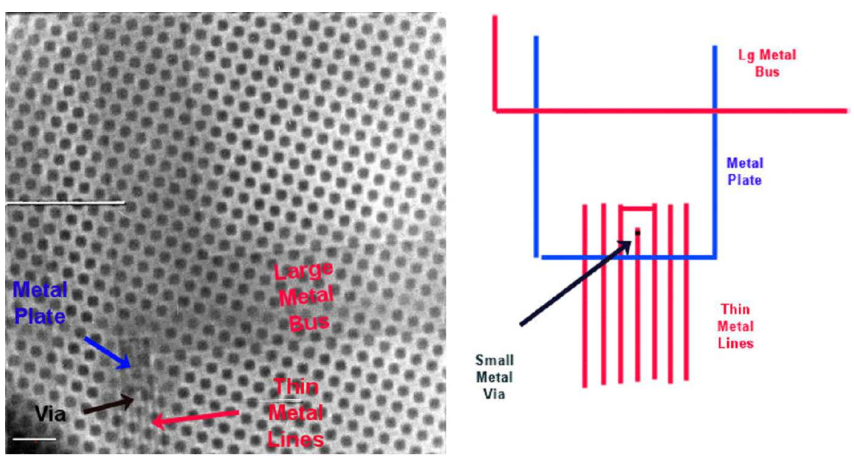

\section{References}

[1] S.H. Lau, H. Chang, J. Cheong, F. Duewer, M. Feser, A. Tkachuk, W. Yun, in: Proc. 25th Army Science Conf., 2006, Orlando (Fl), USA.

[2] S.H. Lau, A. Tkachuk, M. Feser, H. Cui, F. Duewer, W. Yun, in: Proc. LSIT, Osaka (Japan) 2009, Senri Life Science Center, Toyonaka 2009.

Fig. 3. $75 \mu \mathrm{m}$ thick Si chip with $\mathrm{Cu}$ interconnects [2]. 